\title{
Addition of bone morphogenetic protein type 2 to ascorbate and $\beta$-glycerophosphate supplementation did not enhance osteogenic differentiation of human adipose-derived stem cells
}

\author{
Ariadne Cristiane Cabral CRUZ¹, Mariana Lúcia SILVA², Thiago CAON , Cláudia Maria Oliveira SIMÕES
}

\footnotetext{
1- MSc in Dentistry, PhD student, Bioscience and Biotechnology Post-Graduate Program; Professor, Department of Dentistry, Federal University of Santa Catarina, Florianópolis, SC, Brazil.

2- Undergraduated student, Department of Pharmaceutical Sciences, Federal University of Santa Catarina, Florianópolis, SC, Brazil.

3- MSc in Biotechnology, PhD student, Pharmacy Post-Graduate Program, Federal University of Santa Catarina, Florianópolis, Brazil

4- PhD in Pharmacy, Full Professor, Department of Pharmaceutical Sciences, Federal University of Santa Catarina, Florianópolis, SC, Brazil
}

Corresponding address: Cláudia Maria Oliveira Simões - Departamento de Ciências Farmacêuticas - Centro de Ciências da Saúde - Universidade Federal de Santa Catarina - Campus Universitário - Trindade - Florianópolis - SC - 88.040-970 Brazil - Phone: +55 4837215207 - Fax: +55 4837219258 - e-mail: claudias@reitoria.ufsc.br

Received: March 13, 2012 - Modification: August 10, 2012 - Accepted: September 14, 2012

\section{ABSTRACT}

\begin{abstract}
$\mathbf{B}$ one morphogenetic protein type 2 (BMP-2) is a potent local factor, which promotes bone formation and has been used as an osteogenic supplement for mesenchymal stem cells. Objectives: This study evaluated the effect of a recombinant BMP-2 as well as the endogenous BMP-4 and BMP-7 in the osteogenic differentiation of adipose-derived stem cells (ASCs) in medium supplemented with ascorbate and $\beta$-glycerophosphate. Material and Methods: Human ASCs were treated with osteogenic medium in the presence (ASCs+OM+BMP-2) or absence (ASCs+OM) of BMP-2. The alkaline phosphatase (ALP) activity was determined and the extracellular matrix mineralization was evaluated by Von Kossa staining and calcium quantification. The expressions of BMP-4, BMP-7, Smad1, Smad4, and phosphorylated Smad1/5/8 were analyzed by western blotting. Relative mRNA expressions of Smad1, BMP receptor type II (BMPR-II), osteonectin, and osteocalcin were evaluated by qPCR. Results: ASCs+OM demonstrated the highest expression of BMP-4 and BMP-7 at days 21 and 7, respectively, the highest levels of BMPR-II mRNA expression at day 28, and the highest levels of Smad1 mRNA at days 14 and 28. ASCs+OM+BMP-2 demonstrated the highest levels of Smad1 mRNA expression at days 1, 7, and 21, the highest expression of Smad1 at day 7, the highest expression of Smad4 at day 14, the highest ALP activity at days 14 and 21 , and expression of phosphorylated Smad1/5/8 at day 7. ASCs+OM and ASCs+OM+BMP2 showed similar ALP activity at days 7 and 28, similar osteonectin and osteocalcin mRNA expression at all time periods, and similar calcium depositions at all time periods. Conclusions: We concluded that human ASCs expressed endogenous BMP-4 and BMP-7. Moreover, the supplementation of ASCs with BMP-2 did not increase the level of osteogenic markers in the initial (ALP activity), intermediate (osteonectin and osteocalcin), or final (calcium deposition) phases, suggesting that the exogenous addition of BMP-2 did not improve the in vitro osteogenesis process of human ASCs.
\end{abstract}

Key words: Stem cells. Cell differentiation. Osteogenesis. Bone morphogenetic protein 2. Bone morphogenetic protein 4. Bone morphogenetic protein 7. 


\section{INTRODUCTION}

Mesenchymal stem cells (MSCs) have been receiving considerable attention in bone regeneration, both for tissue engineering or cellular therapy. These cells are capable of self-renewal or differentiation into multi-lineage cells, including osteoblasts and condroblasts, under the appropriate conditions. MSCs have been isolated from different tissues, such as bone marrow, dental pulp, fat, and gingiva7,18,26,34,36. Adipose-derived stem cells (ASCs) represent one interesting cellular option for clinical applications since these cells are available in large amounts, are easily accessible and isolated, and they demonstrate a fast attachment and proliferation in culture ${ }^{36}$.

Bone morphogenetic proteins (BMPs) belong to the transforming growth factor $\beta$ (TGF-b) superfamily and were identified by their ability to induce bone formation at ectopic sites ${ }^{28}$. In particular, BMP-2, BMP-4, and BMP-7 have been associated with bone development ${ }^{20}$. BMP-2 has been used for treatment of bone defects in orthopedic, spine, and maxillofacial surgeries ${ }^{1,5}$. Interestingly, it was observed during the fracture repair that an increase of BMP-4 and BMP-7 occurs in response to the presence of $\mathrm{BMP}-2^{27}$, and it was suggested that BMP-4 and BMP-7 might be able to substitute each other during bone healing, as has been shown in other tissues where these BMPs are co-expressed ${ }^{10}$. Therefore, the co-expression of a panel of BMPs exert strong synergy, meaning that combination of certain BMPs may be more efficacious than single BMP to stimulate osteogenic differentiation, and different BMPs may act at different nodal points of osteogenesis ${ }^{5,20}$. Besides the exogenous BMPs, it is important to consider the possibility and the effects of biologically active endogenous BMPs expressed by human MSCs. Seib, et al. ${ }^{22}$ (2009) observed that bone marrow-derived stem cells promoted osteogenesis by endogenous BMP-2, BMP-4, and BMP-6.

Classical signaling pathway for BMPs begins with the binding of BMP to a dimeric complex of transmembrane serine-threonine kinase receptors, the type I and type II receptors. Type I receptors include BMP receptors (BMPRs) -IA, -IB, and activin receptor type 1 (ACTR1), while type II receptors include BMPR-II, ACTR2, and $-2 b$, which are constitutively active kinases. These BMPRs subtypes have different BMP affinities and form receptor complexes prior to or after BMP binding, which is thought to regulate BMP signaling (Smad-dependent versus Smad-independent). Heteromeric receptor complexes comprising type I and II receptors lead to ligand-induced phosphorylation of type I receptors. Following the activation of this receptor, receptor kinases phosphorylate the transcription factors Smad1, 5 or 8 that subsequently form heteromeric complexes with Smad4 and activate the expression of target genes in the nucleus $9,21,23$. Reports have shown that mitogen-activated protein kinase (MAPK) $)^{12}$ and phosphatidylinositol 3-kinase (PI-3K) 16,22 activity are critical switches for osteogenic differentiation, indicating that other pathways, other than the Smad pathway, regulate the mesenchymal stem cells differentiation after BMP exposure.

The most usual supplementation for in vitro osteogenic differentiation includes ascorbate, $\beta$-glycerophosphate, and dexamethasone ${ }^{17,31,36}$. Several studies have used BMP-2 instead of dexamethasone for osteogenic induction 14,22,32. Differently, some reports have demonstrated that in vitro and in vivo treatments of ASCs with BMP-2 had no consistent effect on osteogenic differentiation ${ }^{6,35}$. Therefore, this study evaluated the effect of a recombinant BMP-2 as well as the endogenous BMP-4 and BMP-7 in the osteogenic differentiation of adipose-derived stem cells (ASCs) in medium supplemented with ascorbate and $\beta$-glycerophosphate.

\section{MATERIALS AND METHODS}

\section{Reagents}

Antibiotics/antifungic agentes were purchased from Cultilab (São Paulo, SP, Brazil). Ascorbate, $\beta$-glycerophosphate, BMP-2 (recombinant human BMP-2), eosin, paraformaldehyde, $\rho$-nitrophenol phosphate ( $\rho N P P)$, and silver nitrate were obtained from Sigma-Adrich (St. Louis, MO, USA). $\alpha$-modified Eagle's minimal essential medium ( $\alpha$ MEM modified) and Dulbecco's modified Eagle's medium (DMEM) were from Nutricell (São Paulo, SP, Brazil). Fetal bovine serum, SuperScript ${ }^{\mathrm{TM}}$ III, and Trizol $^{\circledR}$ were purchased from Invitrogen (Carlsbad, CA, USA). Kit Calcium Assay was from BioAssay Systems (Hayward, CA, USA). Antibodies anti -BMP4 (MAB1049), -BMP7 (MAB4350), - $\beta$ actin (04-1116), -Smad1 (05-1459), -phosphorylated Smad1/5/8 (AB3848), -Smad4 (04-1033), anti-rabbit, anti-goat and anti-mouse peroxidase-conjugated antibodies, and Immobilon-P membranes were obtained from Millipore (Danvers, MA, USA). Enhanced chemiluminescence Pierce ECL was from Thermo scientific (Rockford, IL, USA). Step One ${ }^{\circledR}$ detection system and SYBR ${ }^{\circledR}$ Green PCR Master Mix were purchased from Applied Biosystems (Carlsbad, CA, USA). All chemicals were of analytical grade.

\section{Isolation and culture of human adipose- derived stem cells}

After approval by the Institutional Human Ethics Committee (No. 194/06 for adipose-derived stem cells and No. 568/10 for human osteoblasts) and 
with the understanding and written consent of the voluntaries, human lipoaspirate tissues from three healthy patients (average age 21), with normal body mass indexes, non-smokers, and not taking any medication, were processed to isolate the ASCs, as described by Zuk, et al. ${ }^{36}$ (2001). The ASCs were sub-cultured and used at passage 3 , according to the following groups: ASC+OM: Osteogenic medium (OM) (DMEM supplemented with $250 \mu$ M ascorbate and $10 \mathrm{mM} \beta$-glycerophosphate); ASCs+OM+BMP2: OM with $50 \mathrm{ng} / \mathrm{mL}$ BMP-2. MC3T3-E1 preosteoblasts subclone 4 (American Type Culture Collection, Manassas, VA, USA, 2593 ${ }^{\mathrm{TM}}$ ) were used as the positive control for the determination of the alkaline phosphatase activity, the evaluation of matrix mineralization, and for the western blotting assays. MC3T3-E1 cells were cultured according to the recommendations in $\alpha M E M$ modified with 50 $\mu \mathrm{g} / \mathrm{mL}$ ascorbate and $10 \mathrm{mM} \beta$-glycerophosphate ${ }^{33}$. Human osteoblasts were used as the positive control in the qPCR experiments. Human osteoblast explant cultures ${ }^{13}$ were obtained from three patients through biopsies of cortical-porous bone tissue from the mandible, using dental implant drills. Human osteoblasts (passage 6) were cultured with OM. Culture media were supplemented with $10 \%$ ( $\mathrm{v} / \mathrm{v})$ fetal bovine serum and $1 \%(\mathrm{v} / \mathrm{v})$ antibiotic/ antifungic.

\section{Determination of alkaline phosphatase activity}

MC3T3-E1 and ASCs $\left(9.4 \times 10^{4}\right.$ cells/well in 24-well plates) were cultivated for 7, 14, 21, and 28 days. Trizol $^{\circledR}$ was used for total protein extraction, and the concentrations were determined according to the Lowry's method ${ }^{19}$. ALP activity was determined by releasing $\rho$-nitrophenol ( $\rho N P$ ) from $\rho$-nitrophenol phosphate ( $\rho N P P)$. Concisely, 0.5 $\mathrm{mL}$ of diethanolamine buffer $(1.02 \mathrm{M}, \mathrm{pH} 9.8,0.6$ $\mathrm{mM}$ magnesium chloride) and $0.5 \mathrm{~mL}$ of $\rho N P P$ were incubated for $2 \mathrm{~min}$ at $37^{\circ} \mathrm{C}$. Afterward, $0.1 \mathrm{~mL}$ of the extracted protein was added and incubated at $37^{\circ} \mathrm{C}$. Following $30 \mathrm{~min}, 1 \mathrm{~mL}$ of $3 \mathrm{~N} \mathrm{NaOH}$ was used to stop the reaction. Absorbances were measured (Infinite M200, TECAN, Salzburg, Grödig, Austria) at $405 \mathrm{~nm}$, and the ALP activity was calculated from a pNP standard curve and all values were normalized against the total protein concentration.

\section{Evaluation of matrix mineralization}

Von Kossa staining determined the presence of phosphate at the extracellular matrix. MC3T3-E1 and ASCs ( $2 \times 10^{4}$ cells/well on a 96 -well plates) were cultivated for 21 days. Cells were fixed for $1 \mathrm{~h}$ with $3 \%(\mathrm{v} / \mathrm{v})$ aqueous paraformaldehyde and stained with $1 \%(\mathrm{w} / \mathrm{v})$ silver nitrate under light exposure for $1 \mathrm{~h}$, and counterstained with eosin.

MC3T3-E1 and ASCs ( $2 \times 10^{4}$ cells/well on 96-well plates) were cultivated for 5, 12, 23, and 32 days, for the calcium quantification at the extracellular matrix. Cells were harvested in $200 \mu \mathrm{L}$ of $0.1 \mathrm{~N} \mathrm{HCl}$ at $4^{\circ} \mathrm{C}$ for $4 \mathrm{~h}$ and centrifuged at $10,000 \times \mathrm{g}$ for 5 min. The Kit Calcium Assay was used for measuring the supernatant total calcium.

\section{Western blotting}

MC3T3-E1 and ASCs $\left(9.4 \times 10^{4}\right.$ cells/well on 24 well-plates) were cultivated for 7, 14, 21, and 28 days. Following cells lysis, the protein quantification was performed. For the western blotting experiments, $5 \mu \mathrm{g}$ of denatured protein were loaded onto an SDS/polyacrylamide gel. Proteins were transferred to Immobilon-P membranes, which were incubated overnight with anti -Smad1 (1:500), -phosphorylated Smad1/5/8 (1:500), -Smad4 (1:1000), -BMP4 (1:500), -BMP7 (2 $\mu \mathrm{g} / \mathrm{mL})$, or $-\beta$ actin $(1: 2000)$ antibodies. After incubation with each corresponding secondary antibody, the enhanced chemiluminescence Pierce ECL substrate was used for detection, according to the manufacturer's protocol.

\section{qPCR}

Human osteoblasts and ASCs $\left(9.4 \times 10^{4}\right.$ cells/well) were cultured for $1,7,14,21$, and 28 days on 24-well plates. Total RNA was isolated with Trizol $^{\circledR}$ reagent, and CDNA transcriptions were performed using oligo (dT) primers and SuperScript ${ }^{T M}$ III. Step One ${ }^{\circledR}$ detection system and SYBR ${ }^{\circledR}$ Green PCR Master Mix were used for the qPCR. The comparative threshold cycle (Ct) method was used in order to quantify changes in the Smad1, BMPR-2, Osteonectin, and Osteocalcin gene expression between the control (human osteoblasts) and treated ASCs. The fold difference between the control and treatments was calculated according to $2-\Delta \Delta \mathrm{Ct}$, where $\Delta \Delta \mathrm{Ct}=(\Delta \mathrm{Ct}$ control $)-(\Delta \mathrm{Ct}$ treatment $)$ and $\Delta \mathrm{Ct}=(\mathrm{Ct}$ target gene) - (Ct internal control, ribosomal 18 s). BMPR-II mRNA expression: Primer forward 5'-3' TGAAAAGATCAAGAAACGTGTGAAA. Primer reverse 5'-3' GCCCTGTTACTGCCATTATTGTT; Smad1 mRNA expression: Primer forward GGGACTGCCTCATGTCATTTACT. Primer reverse CAGACCTCCTTCTGCTTGGAA; Osteocalcin mRNA relative expression: Primer forward AGGGCAGCGAGGTAGTGAAG. Primer reverse AACTCGTCACAGTCCGGATTG; Osteonectin mRNA expression: Primer forward CGGGTGAAGAAGATCCATGAG. Primer reverse CTGCCAGTGTACAGGGAAGATG.

\section{Statistical analysis}

All experiments were performed in triplicate to confirm the reproducibility of the results. The results of the ALP activity and calcium quantification in all groups were compared through non-parametric 
one-way analysis of variance (ANOVA) followed by the Student Newman-Keuls (SNK) post hoc test. Results of mRNA relative expression in all groups were compared through the Student's $t$ test. Statistical analyses were performed comparing all treatments for each time period separately using the GraphPad Prism 4 software (Graph Pad Software Inc, San Diego, CA, USA) at a 95\% confidence interval.

\section{RESULTS}

\section{BMP-2 improved the alkaline phosphatase activity}

$\mathrm{ASCS}+\mathrm{OM}$ and $\mathrm{ASC}+\mathrm{OM}+\mathrm{BMP} 2$ demonstrated similar ALP activities, and MC3T3-E1 cells (positive control) showed the highest activity $(\rho=0.0004)$ at day 7. ASCs+OM+BMP2 up-regulated the ALP activity compared to ACS+OM and MC3T3-E1 at day $14(\rho=0.00379)$. At day 21, ASCs+OM+BMP2 and MC3T3-E1 demonstrated the highest activities $(\rho=0.0087)$. There was no statistically significant difference among the groups at day $28(\rho>0.05)$ (Figure 1).

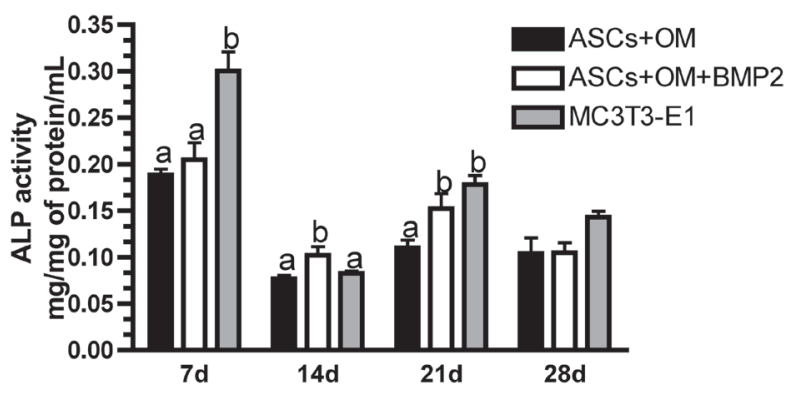

Figure 1-Alkaline phosphatase (ALP) activity. Enzymatic activity at days $7,14,21$, and 28 . Different letters refer to statistical significant differences (ANOVA/SNK, $\rho<0.05$ )
BMP-2 did not improve the calcium at the extracellular matrix

Von Kossa staining demonstrated that all groups presented phosphate at the extracellular matrix at day 21 (Figure 2A-C).

At day 5, calcium deposition was not observed at the extracellular matrix. At day 12, MC3T3-E1 demonstrated the highest calcium amount $(\rho<0.0001), A S C s+O M$ and ASCs+OM+BMP2 showed similar results. There was no statistically significant difference among the groups ( $\rho>0.05)$ at days 23 and 32 (Figure 2D).

\section{Expression of osteoblast-related proteins}

ASCs+OM+BMP2 expressed more Smad1 when compared to MC3T3-E1 and ASCs+OM at day 7. At days 14 and 21, all groups demonstrated similar Smad1 expressions. ASCs+OM demonstrated the lowest expression at day 28 (Figure 3).

Only MC3T3-E1 expressed phosphorylated Smad1/5/8 at day 7. All groups demonstrated similar expression of these proteins at day 14 . At day 21, ASCs+OM+BMP2 expressed more than ASCs+OM, while MC3T3-E1 stopped these expressions. All groups had no expression of these phosphorylated proteins at day 28 (Figure 3).

ASCs+OM showed the highest Smad4 expression at day 7. At day 14, MC3T3-E1 demonstrated the highest expression followed by ASCs+OM+BMP2 and then by ASCS+OM. MC3T3-E1 demonstrated the highest level of Smad4 at day 21, followed by ASCs+OM and then by ASCs+OM+BMP2. At day 28, MC3T3-E1 showed the highest expression, while ASCs+OM and ASCs+OM+BMP2 demonstrated similar levels of Smad4 (Figure 3).

All groups had no expression of BMP-4 at day 7. At day 14, ASCs+OM and ASCs+OM+BMP2 demonstrated similar expressions, while MC3T3-E1 had no expression. ASCs+OM demonstrated the highest BMP-4 expression followed by ASCs+OM+BMP2 and then MC3T3-E1 at day

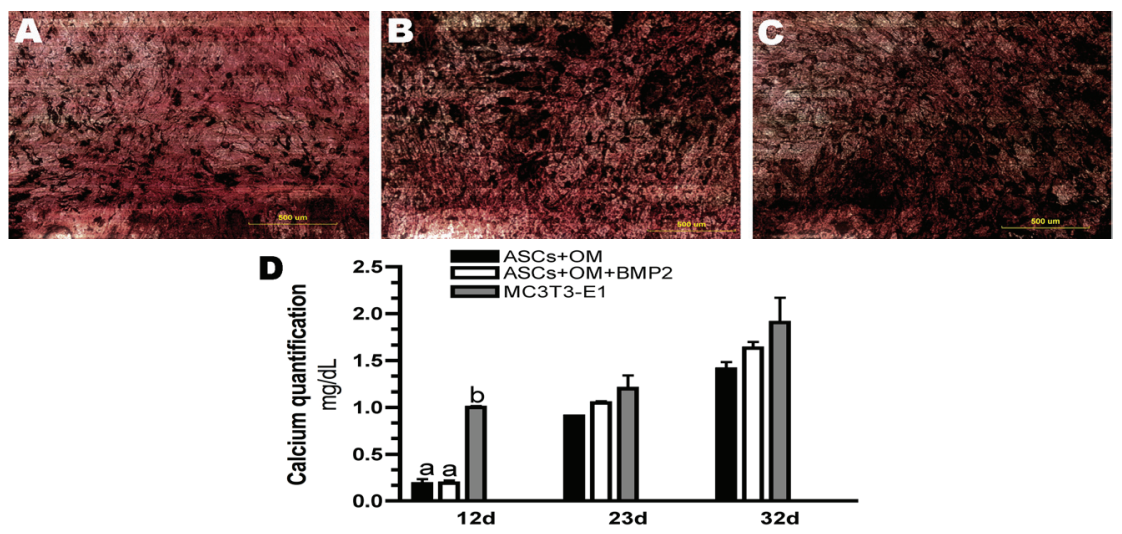

Figure 2- Extracellular matrix mineralization. A) Von Kossa staining. Adipose-derived stem cells (ASCs) with osteogenic medium (OM). Bar=500 $\mu \mathrm{m}$; B) ASCs with OM supplemented with BMP-2; C) MC3T3-E1 cells (positive control); D) Calcium quantification at days 12,23 , and 32 . Different letters refer to statistical significant differences (ANOVA/SNK, $\rho<0.05$ ) 


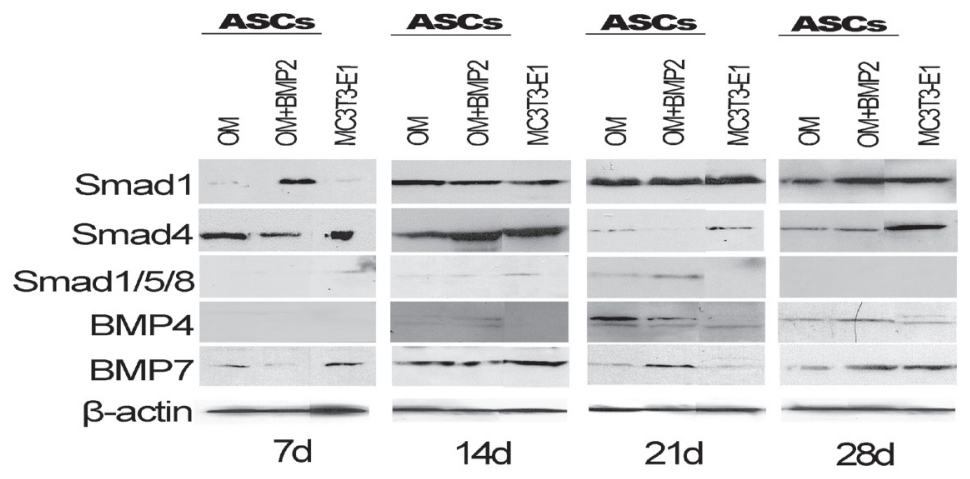

Figure 3- Expression of osteoblast related proteins. Protein expression evaluated by western blotting, at days 7, 14, 21, and 28
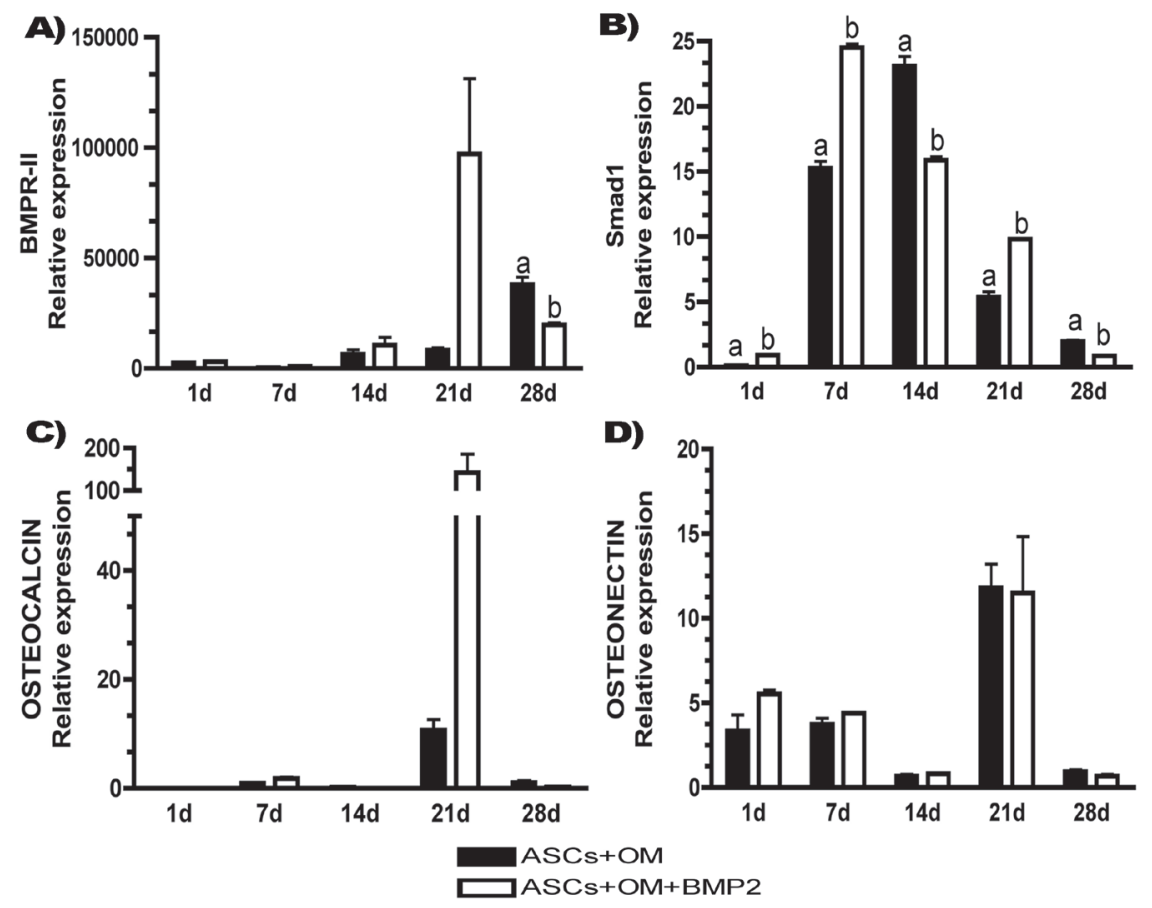

Figure 4- mRNA relative expression. A) BMPR-II mRNA expression; B) Smad1 mRNA expression; C) Osteocalcin mRNA relative expression; D) Osteonectin mRNA expression. Different letters refer to statistical significant differences ( $T$ test, $\rho<0.05)$

21. Figure 3 did not show differences between ASCs+OM and ASCs+OM+BMP2 groups at day 28, while MC3T3-E1 demonstrated a weak expression.

ASCs+OM+BMP2 expressed the lowest BMP-7 levels at day 7. The expressions were similar for all groups at day 14 . At day $21, \mathrm{ASC}+\mathrm{OM}+\mathrm{BMP} 2$ showed the highest expression of this protein. ASCs+OM BMP-7 expressions were smaller than the other groups at day 28 (Figure 3).

\section{Relative expression of osteoblast-related mRNA}

Figure 4A shows that BMPR-II relative mRNA expressions were similar for $A \mathrm{SCS}+\mathrm{OM}$ and ASCs+OM+BMP2 ( $\rho>0.05)$ at days 1, 7, 14, and 21. At day $28, \mathrm{ASCs}+\mathrm{OM}$ demonstrated the highest expression $(\rho=0.0118)$.
ASCs+OM+BMP2 showed the highest levels of Smad1 relative mRNA expression at days $1(\rho<0.0001)$, $7(\rho=0.0002)$, and $21(\rho=0.0008)$. ASCs+OM demonstrated the highest expressions at days 14 $(\rho=0.0014)$ and $28(\rho=0.0003)$ (Figure 4B).

Osteocalcin and Osteonectin relative mRNA expressions were similar for all groups for all time periods ( $\rho>0.05$ ) (Figure 4C and 4D).

\section{DISCUSSION}

BMP-2 is considered a potent local factor that promotes bone formation ${ }^{1}$ and has been used as an osteogenic supplementation ${ }^{14,22,32}$. This report evaluated the effects of BMP-2 associated with ascorbate and $\beta$-glycerophosphate to induce osteogenic differentiation of human ASCs during 
the entire in vitro osteogenic process (day 1 to 32 ), and the effects of endogenous BMP-4 and BMP-7 in this process. Herein, efforts were made to study osteogenic markers, such as ALP activity, Smads, BMPR-II, osteonectin, osteocalcin, and calcium deposition, as discussed below.

An enzymatic hydrolysis activity of ALP is necessary to initiate biological mineralization by hydrolyzing $\beta$-glycerophosphate, which serves as an additional source of phosphate ions ${ }^{25}$. Some proteins are involved in the extracellular matrix deposition and mineralization during bone formation, such as osteonectin and osteocalcin. Osteonectin is an intermediate phase glycoprotein that binds calcium and type I collagen with a high affinity. Osteocalcin is produced exclusively in bone, dentin, and cementum and it represents approximately $20 \%$ of non-collagenous proteins ${ }^{11}$. Finally, a functional assay of terminally differentiated osteoblasts is the extracellular matrix mineralization, which can be evaluated by the calcium quantification.

In general, we observed that the supplementation with BMP-2 did not increase the levels of osteogenic markers in the initial, intermediate, or final phases of human ASCs differentiation. Our results demonstrated that these cells expressed endogenous BMP-4 and BMP-7, and we were encouraged to suggest that these endogenous BMPs were biologically active due to the observed induction of ALP activity, upregulation of osteogenic genes (osteocalcin and osteonectin), and increase of calcium deposition in cells treated without BMP-2. Conversely, Seib, et al. ${ }^{22}$ (2009) observed that human bone marrow-derived mesenchymal cells were able to express endogenous BMP-4, but not BMP-7. These observed differences may be attributed to the different cell lines used.

Herein, the peak of ALP activity, which indicates the initial phase of extracellular matrix mineralization, occurred at day 7. At that stage, ASCs treated in the presence or absence of BMP-2 demonstrated similar results, suggesting that BMP-2 supplementation did not improve the initial phase of osteogenic differentiation, in accordance with Song, et al.24 (2007) (human bone marrow-derived stem cells) and differing from Wang, et al. ${ }^{30}$ (2010) (rat bone marrow stromal cells). It is important to appreciate that explanations made with BMPs in human cells can be extrapolated to the human system with more precision $^{22}$.

The presence of BMP- 2 in medium supplementation did not up-regulate the BMPR-II mRNA expression, similarly to that found by Wang, et al. ${ }^{30}$ (2010). We also observed a similar expression of osteocalcin and osteonectin mRNA relative expression for ASCs treated with or without BMP-2. Zuk, et al. ${ }^{35}$ (2011) demonstrated that induction of ASCs with OM containing BMP-2 for 7 days significantly augmented expression of osteopontin and osteocalcin, and decreased ALP and osteonectin gene expressions. However, when the exposure time to BMP-2 was increased to either 21 or 28 days (the terminal differentiation stages of ASCs) any changes to the gene expression, attributable to BMP-2 was lost. Wan, et al. ${ }^{29}$ (2006) observed similar osteonectin expression in mouse ASCs cultures using control medium and osteogenic medium with BMP-2. Complementary, our results demonstrated that ASCs treated with or without exogenous BMP-2 showed similar calcium deposition at the extracellular matrix, as found by Song, et al. ${ }^{24}$ (2007) and Zuk, et al. ${ }^{35}$ (2011). Conversely, Beloti and Rosa ${ }^{3}$ (2005) demonstrated that osteoblast differentiation of human bone marrow cells did not occur only in the presence of ascorbate and $\beta$-glycerophosphate. Khanna-Jain, et al. ${ }^{15}$ (2010) observed that the addition of BMP-2 or BMP-6 to dexamethasone, ascorbic acid, and $\beta$-glycerophosphate did not enhance osteogenic differentiation of human periodontal ligament cells, since they observed that neither of the BMPs induced in vitro mineralization, despite the increase of ALP activity.

BMP-2 supplementation led to the highest levels of Smad1 relative mRNA expression at days 1,7 , and 21 , the highest expression of Smad1 at day 7, and the highest expression of Smad4 at day 14. Chang, et al. ${ }^{4}$ (2009) demonstrated that the treatment of osteoblast-like cells with BMP-4 increases Smad1/5 phosphorylation. Aoki, et al. ${ }^{2}$ (2001) also observed that the BMP-4 activation in $\mathrm{C} 2 \mathrm{C} 12$ mouse muscle myoblast cell line occurs via the Smad pathway. We did not observe an association between the BMP4 expression and Smads1/5/8 phosphorylation. Supporting our results, Seib, et al. ${ }^{22}$ (2009) demonstrated that osteogenesis by endogenous BMP-4 and BMP- 6 was independent of Smad activation and dependent on phosphatidylinositol 3-kinase (PI-3K) activation in marrow-derived stem cells. Therefore, BMP-4 activation has been related to pathways dependent or independent of Smads. These different findings may be due to the different lineage cell type, species, and culture conditions. Zuk, et al. ${ }^{35}$ (2011) did not observe any significant changes in Smad1/5/8 phosphorylation levels upon BMP-2 induction. Additionally, these authors observed that the removal of dexamethasone from the BMP-2 did not significantly change the mineralization capacity of ASCs from that measured when samples were induced with BMP-2 and OM containing dexamethasone. Such a finding would suggest that the lack of effect of BMP-2 was not due to any interference by the presence of dexamethasone.

Despite that the presence of BMP-2 in the osteogenic supplementation led to the highest expression of Smads, this protein did not increase the ALP activity at the peak of this enzyme, the 
expression of osteonectin and osteocalcin mRNA, or the calcium deposition at the extracellular matrix, an indicator of osteoblast final maturation. Conversely, Dragoo, et al. ${ }^{8}$ (2003) observed that ASCs cultured with BMP-2 demonstrated more ALP and matrix calcification than the positive osteoblast control. Considering that both treatments (ASCs+OM and ASCs+OM+BMP2) led to similar effects in osteogenic differentiation, the effects of exogenous BMP-2 could be counterbalanced by the highest expression of endogenous BMP-4 and BMP-7. Herein, probably endogenous BMP-4 and BMP-7 pathways were independent of Smad activation, corroborating Seib, et al.22 (2009). There are a number of possible explanations for the reasons that ASCS had demonstrated similar osteogenic differentiation in the presence or absence of BMP-2, including the maturation of osteogenic progenitors during culture, emergence of a dominant cell type or spontaneous differentiation of MSCs into the osteoblasts 22,24 . Although a combination of these factors could be responsible for the results herein, endogenous BMPs production could be a critical factor in any of these scenarios.

\section{CONCLUSIONS}

We concluded that human ASCs expressed endogenous BMP-4 and BMP-7. Moreover, the supplementation of ASCs with BMP-2 did not increase the level of osteogenic markers in the initial (ALP activity), intermediate (osteonectin and osteocalcin), or final (calcium deposition) phases suggesting that the exogenous addition of BMP-2 did not improve the in vitro osteogenesis process of human ASCs.

\section{ACKNOWLEDGEMENTS}

The authors would like to thank to CNPq/MCT and CAPES/MEC (Brazil) for their research fellowships. We thank Dr. William F. Zambuzzi (Universidade do Grande Rio) for gently providing the MC3T3-E1 cells. The authors would also like to thank MSc Lucas Barcelos Oliveira for his proficient editorial assistance. This work was partially supported by MCT/SEBRAE/ FINEP (grant number 23080.039510/2007-12). The authors disclaim no conflicts of interest in this study.

\section{REFERENCES}

1- Alonso N, Tanikawa DY, Freitas RS, Canan L Jr, Ozawa TO, Rocha DL. Evaluation of maxillary alveolar reconstruction using a resorbable collagen sponge with recombinant human bone morphogenetic protein-2 in cleft lip and palate patients. Tissue Eng Part C Methods. 2010;16:1183-9.

2- Aoki H, Fujii M, Imamura T, Yagi K, Takehara K, Kato M, et al. Synergistic effects of different bone morphogenetic protein type I receptors on alkaline phosphatase induction. J Cell Sci. 2001; 114:1483-9.
3- Beloti MM, Rosa AL. Osteoblast differentiation of human bone marrow cells under continuous and discontinuous treatment with dexamethasone. Braz Dent J. 2005;16:156-61.

4- Chang SF, Chang TK, Peng HH, Yeh YT, Lee DY, Yeh CR, et al. BMP-4 induction of arrest and differentiation of osteoblastlike cells via p21 CIP1 and p27 KIP1 regulation. Mol Endocrinol. 2009;23:1827-38.

5- Cho TJ, Gerstenfeld LC, Einhorn TA. Differential temporal expression of members of the transforming growth factor beta superfamily during murine fracture healing. ] Bone Miner Res. 2002;17:513-20.

6- Chou YF, Zuk PA, Chang TL, Benhaim P, Wu BM. Adipose-derived stem cells and BMP2: part 1. BMP2-treated adipose-derived stem cells do not improve repair of segmental femoral defects. Connect Tissue Res. 2011;52:109-18.

7- Demarco FF, Conde MC, Cavalcanti BN, Casagrande L, Sakai VT, Nör JE. Dental pulp tissue engineering. Braz Dent J. 2011;22:3-13. 8- Dragoo JL, Choi JY, Lieberman JR, Huang J, Zuk PA, Zhang J, et al. Bone induction by BMP-2 transduced stem cells derived from human fat. J Orthop Res. 2003;21:622-9.

9- Fujii M, Takeda K, Imamura T, Aoki H, Sampath TK, Enomoto $S$, et al. Roles of bone morphogenetic protein type I receptors and Smad proteins in osteoblast and chondroblast differentiation. Mol Biol Cell. 1999;10:3801-13.

10- Gerstenfeld LC, Cullinane DM, Barnes GL, Graves DT, Einhorn TA. Fracture healing as a post-natal developmental process: molecular, spatial, and temporal aspects of its regulation. J Cell Biochem. 2003;88:873-84.

11- Ivanovski S, Haase HR, Bartold PM. Expression of bone matrix protein mRNAs by primary and cloned cultures of the regenerative phenotype of human periodontal fibroblasts. J Dent Res. 2001;80:1665-71.

12- Jaiswal RK, Jaiswal N, Bruder SP, Mbalaviele G, Marchak DR, Pittenger $M$. Adult human mesenchymal stem cell differentiation to the osteogenic or adipogenic lineage is regulated by mitogenactivated protein kinase. J Biol Chem. 2000;275:9645-52.

13- Jonsson KB, Frost A, Nilsson O, Ljunghall S, Ljunggren O. Three isolation techniques for primary culture of human osteoblast-like cells: a comparison. Acta Orthop Scand. 1999;70:365-73.

14- Kang SW, La WG, Kang JM, Park JH, Kim BS. Bone morphogenetic protein-2 enhances bone regeneration mediated by transplantation of osteogenically undifferentiated bone marrowderived mesenchymal stem cells. Biotechnol Lett. 2008;30:11638.

15- Khanna-Jain R, Agata H, Vuorinen A, Sándor GK, Suuronen $\mathrm{R}$, Miettinen S. Addition of BMP-2 or BMP- 6 to dexamethasone, ascorbic acid, and beta-glycerophosphate may not enhance osteogenic differentiation of human periodontal ligament cells. Growth Factors. 2010;28:437-46.

16- Kratchmarova I, Blagoev B, Haack-Sorensen M, Kassem M, Mann M. Mechanism of divergent growth factor effects in mesenchymal stem cell differentiation. Science. 2005;308:1472-7. 17- Levi B, Nelson ER, Brown K, James AW, Xu D, Dunlevie R, et al. Differences in osteogenic differentiation of adipose-derived stromal cells from murine, canine, and human sources in vitro and in vivo. Plast Reconstr Surg. 2011;128:373-86.

18- Long MW. Osteogenesis and bone-marrow-derived cells. Blood Cells Mol Dis. 2001;27:677-90.

19- Lowry O, Rosebrough N, Farr A, Randall R. Protein measurement with the Folin phenol reagent. J Biol Chem. 1951;193:265-75.

20- Luu HH, Song WX, Luo X, Manning D, Luo J, Deng ZL, et al. Distinct roles of bone morphogenetic proteins in osteogenic differentiation of mesenchymal stem cells. J Orthop Res. 2007;25:665-77.

21- Qing J, Zhang Y, Derynck R. Structural and functional characterization of the transforming growth factor-beta -induced Smad3/c-Jun transcriptional cooperativity. J Biol Chem. $2000 ; 275: 38802-12$. 
22- Seib FP, Franke $M$, Jing D, Werner C, Bornhäuser $M$. Endogenous bone morphogenetic proteins in human bone marrowderived multipotent mesenchymal stromal cells. Eur J Cell Biol. 2009;88:257-71.

23- Song B, Estrada KD, Lyons KM. Smad signaling in skeletal development and regeneration. Cytokine Growth Factor Rev. 2009;20:379-88.

24- Song SJ, Jeon O, Yang HS, Han DK, Kim BS. Effects of culture conditions on osteogenic differentiation in human mesenchymal stem cells. J Microbiol Biotechnol. 2007;17:1113-9.

25- Sugawara Y, Suzuki K, Koshikawa M, Ando M, Iida J. Necessity of enzymatic activity of alkaline phosphatase for mineralization of osteoblastic cells. Jpn J Pharmacol. 2002;88:262-9.

26- Telles PD, Machado MA, Sakai VT, Nör JE. Pulp tissue from primary teeth: new source of stem cells. J Appl Oral Sci. 2011;19:189-94.

27- Tsuji K, Cox K, Gamer L, Graf D, Economides A, Rosen V. Conditional deletion of BMP7 from the limb skeleton does not affect bone formation or fracture repair. J Orthop Res. 2010;28:384-9. 28- Urist MR. Bone: formation by autoinduction. Science. 1965; 150:893-9.

29- Wan D, Shi YY, Nacamuli RP, Quarto N, Lyons KM, Longaker ML. Osteogenic differentiation of mouse adipose-derived adult stromal cells requires retinoic acid and bone morphogenetic protein receptor type IB signaling. Proc Natl Acad Sci USA. 2006;103:12335-40.
30- Wang A, Ding X, Sheng S, Yao Z. Bone morphogenetic protein receptor in the osteogenic differentiation of rat bone marrow stromal cells. Yonsei Med J. 2010;51:740-5.

31- Wang A, Ding X, Sheng S, Yao Z. Retinoic acid inhibits osteogenic differentiation of rat bone marrow stromal cells. Biochem Biophys Res Commun. 2008;375:435-9.

32- Yamaguchi A, Komori T, Suda T. Regulation of osteoblast differentiation mediated by bone morphogenetic proteins, hedgehogs, and Cbfa1. Endocr Rev. 2000;21:393-411.

33- Zambuzzi WF, Yano CL, Cavagis AD, Peppelenbosch MP, Granjeiro JM, Ferreira CV. Ascorbate-induced osteoblast differentiation recruits distinct MMP-inhibitors: RECK and TIMP-2. Mol Cell Biochem. 2009;322:143-50.

34- Zhang QZ, Su WR, Shi SH, Wilder-Smith P, Xiang AP, Wong $A$, et al. Human gingiva-derived mesenchymal stem cells elicit polarization of $\mathrm{m} 2$ macrophages and enhance cutaneous wound healing. Stem Cells. 2010;28:1856-68.

35-- Zuk P, Chou YF, Mussano F, Benhaim P, Wu BM. Adiposederived stem cells and BMP2: part 2. BMP2 may not influence the osteogenic fate of human adipose-derived stem cells. Connect Tissue Res. 2011;52:119-32.

36- Zuk PA, Zhu M, Mizuno H, Huang J, Futrell W, Katz AJ, et al. Multilineage cells from human adipose tissue: implications for cell-based therapies. Tissue Eng. 2001;7:211-28. 